\title{
1. Responsible innovation in digital health
}

\section{Tatiana Iakovleva, Elin M. Oftedal and John Bessant}

There is only one way to look at things until someone shows us how to look at them with different eyes. Pablo Picasso

\subsection{INTRODUCTION}

There is little doubt that healthcare is in crisis. On the one hand there have been enormous advances in the nature and quality of care, several illnesses have been eradicated or minimized and lifespans have been extended to the point where some predict that the ' 100 year life' will be a realistic possibility for many children born today (Gratton and Scott, 2016). But, on the other hand many of these gains are becoming hard to sustain because of powerful forces on the demand side.

Healthcare costs and spending often rise at rates exceeding inflation, and are expected to increase in the future. For example, estimates suggests that aggregate healthcare spending in the United States will grow at an average annual rate of 5.8 per cent from 2015 through 2025 (Keehan et al., 2017). The health sector faces many challenges today and represents a significant cost of at least 10 per cent of GDP in the countries' economies. This situation is likely to worsen as a result of an aging population, rising prices and increasing complexity associated with technology in the health services (Marmot et al., 2012), where there is pressure on delivering qualitatively good services to all, while significantly reducing costs. Despite wide variations in healthcare funding systems the underlying trends are the same across countries.

Against this backdrop the need for disruptive innovation is clear and extensive efforts are being made to find a way out of the crisis through innovative new approaches. A major candidate here is 'digital healthcare' - an umbrella label for a wide range of technologies that could meet the healthcare challenges. Examples include various apps, telemedicine, electronic medical 
records, 'smart' homes and 'connected medicine'. The novelty of the field and the pace of underlying technological development means that both established companies and start-ups are engaging in this sector and empower patients to be a part of this development.

The technology allows for a reduction of costs due to remote processes and ability to treat a higher number of patients. Further, digital tools allow for the move to 'consumer-centric' healthcare, allowing citizens to take responsibility for managing their healthcare and that of their families. Their potential is significant - not just in terms of improving productivity within the healthcare delivery sector but also in offering better outcomes, higher quality and reliability, greater patient autonomy and higher quality of life.

Taken at face value digital healthcare appears to offer a rosy future for patient-centred high quality healthcare delivery at an affordable cost and open to all. But, the promise of digitalization might not be attained unless we are aware of its challenges. What if these miraculous technological developments are abused, exposing society to the 'dark side' of digital innovations? For example, electronic records and big data diminish privacy, and could lead to screening and refusal of care. Intelligent homes may not be designed around patients, but for the convenience of the 'system' and give the patient an experience more akin to prison than home or hospital, monitored and managed by robots and sensors. Automated systems might increasingly make their own decisions about treatment and even life and death.

This raises an old question - the role of responsibility in decisions about technological innovation. It is timely to shift attention from 'how to achieve ground-breaking innovation' towards 'how to achieve ground-breaking innovation in a responsible manner'.

\subsection{RESPONSIBLE INNOVATION}

For more than fifty years researchers have been arguing for approaches which involve some degree of technology assessment and control, focusing on tools that allow anticipation and exploration of likely consequences of technology decisions. Discussions around this theme go back at least to the 1970s with the 'Science, technology and society' (STS) movement and the establishment of key influential organizations such as the Science Policy Research Unit at the University of Sussex (Cole et al., 1973). Its most recent manifestation can be seen in work on 'responsible innovation' (Owen, Bessant and Heintz, 2013). 'Responsible innovation' (RI) can be defined as 'a transparent, interactive process by which societal actors and innovators become mutually responsive to each other with a view to the (ethical) acceptability, sustainability and societal desirability of the innovation process and its marketable products (in order 
to allow a proper embedding of scientific and technological advances in our society)' (von Schomberg, 2011, p.9).

Thus, the focus of RI is on considering alternative outcomes and engagement of multiple stakeholders early in the innovation process. A helpful framework focused on four dimensions of responsible innovation is offered by Stilgoe, Owen and Macnaghten (2013) which looks at anticipation of risks, user inclusiveness, reflexivity and responsiveness.

In outline, these cover questions like:

Have the consequences of implementing the innovation been explored? What alternative scenarios might there be? (anticipation);

Have the 'owners' of the business model been sufficiently reflective in exploring and developing it -or does it represent a single perspective or an implicit dominant design? (reflexivity);

Does the model take into account the inputs of relevant stakeholders? (inclusivity) and

Can the innovation be adapted in response to the answers to these questions, is there flexibility in delivery? (responsiveness)

\subsection{USER INCLUSION - THE MISSING LINK IN HEALTHCARE INNOVATION?}

The third dimension is of particular relevance in our healthcare context. In the process of organizing healthcare as a system, trying to meet the varied and complex needs of many different individuals there is a risk that the connection to the end-user, the patient, gets lost. The increasing professionalization of healthcare and the rising sophistication of the technology involved has meant that the 'voice of the patient' has often been drowned out. Instead, patient input to the innovation process is being replaced with a passive status which sees them as recipients of healthcare rather than able to shape it.

There is growing recognition of this divide and the rhetoric within many healthcare systems is now around bringing the patient back into the equation. There are several reasons why this might be a timely move; first there is good evidence that involving patients leads to better design because they understand their needs best. Research suggests that patient-led innovation has a strong track record of success, not least because articulating tacit knowledge about the patient experience and then building that into design of new solutions can enrich those solutions and make them compatible with a wider downstream set of users (Oliveira et al., 2018). Increasingly patients are being seen not as passive consumers of healthcare but as active partners in its creation and delivery. 
Considering the user dimension also helps us explore a paradox associated with healthcare technology. As Hwang and Christensen (2008), argue, despite so many sophisticated medical technologies introduced every year, healthcare has not been disrupted to a significant degree. Their view is that this happens because technology has almost always been implemented in a sustaining manner in healthcare - primarily to help hospitals and doctors to solve the most complex problems. As a consequence most technological enablers have failed to bring about lower costs, higher quality and greater accessibility (Christensen, Waldeck and Fogg, 2017).

The theory of disruptive innovation suggests that new trajectories emerge at the edges of the mainstream, working with users who are not served or underserved in the current provision. Arguably, bringing this group of stakeholders into the development equation might open up the possibilities for significant shifts in healthcare performance, enabling radical changes of the kind which are urgently needed.

The potential for significant change through user involvement is there; the question is to what extent is it, or can it be realized? One risk with the powerful new technologies we list above is that patients might become further marginalized - healthcare is something done to them and delivered in an increasingly non-human fashion. An alternative view is to put the patient at the centre and explore models which would empower them to shape and direct the technologies in their own interests. And that begs a second question - how to empower users to become a part of innovation process?

\subsection{OVERVIEW OF THE BOOK}

This book tries to explore the question of responsible innovation in the emerging field of digital healthcare and focuses particularly on the challenge of increasing user engagement in the process. It draws on a variety of case examples of innovations in digital health from six different countries - Brazil, the Netherlands, Norway, Portugal, UK and USA. ${ }^{1}$

In Chapter 2, we introduce the theoretical construct of responsibility and its implications for the firm-level innovation process. Chapter 3 discusses the context for digital healthcare and compares different healthcare systems, analysing the power centres and the role of patients in such systems. We suggest that patients are not a homogeneous group in terms of their innovation behaviour. Instead there is a spectrum of behaviours - from passive recipients of healthcare services through to the 'informed' patient, who is equipped to use technology based on improved understanding. Beyond this, and enabled by digital technology, the 'involved patient' can play an active role within a wider healthcare delivery system by actively providing feedback to it. At the 
very extreme of this spectrum we find the 'innovative patient', who supplies ideas of their own based on their deep understanding of their healthcare issues.

Chapter 4 to 14 of this book provide empirical examples of digital healthcare innovations and discusses four dimensions of RI in each of them. Chapter 4 written by Pedro Oliveira, Salomé Azevedo and Helena Canhão illustrates that patients all over the world can be real innovators and entrepreneurs. The social media platform 'Patient Innovation.com' described in this chapter gathered over 800 innovative solutions developed by patients from over 70 different countries. The platform enables patients to share their solutions and help innovation diffusion.

Chapter 5 by Thomas Laudal and Tatiana Iakovleva discusses how patient feedback can potentially lead to service innovations in hospitals, looking at the example of a Norwegian hospital. It also debates how the introduction of digital communication channels like electronic health records (EHR) can trigger this process. The authors identify three questions for future research: What kind of relationship is there between the release of EHRs and patient feedback? How do patient-initiated innovations influence hospital performance? And, what are the most important contextual factors?

Chapter 6 written by Bala Mulloth and Michael D. Williams illustrates how patients can become more informed and involved in their care by describing the University of Virginia (USA) digital healthcare application. The authors analyse the process through the lens of responsible innovation and present the challenges to realizing the full potential of this type of EHR.

Chapter 7 by John Bessant, Allen Alexander, Danielle Wynne and Anna Trifilova explores the theme of 'design space' around digital innovations. Using the particular example of a detailed longitudinal case of the development and diffusion of a digital health information platform the authors identify a number of key points at which the innovation concept 'pivoted' to reflect new information, some of which resulted from a wider level of inclusion.

In Chapter 8 Raj Kumar Thapa and Tatiana Iakovleva addresses the question of how business organizations pursue responsible innovation in business development and create positive social impact. Based on an explorative case study of a privately owned Norwegian firm within a medical industry, this chapter analyses purpose, process, and outcomes of the innovation process on the firm level from the responsibility point of view.

Chapter 9 written by Dagfinn Wåge and Andrea Marie Stangeland describes the development of the application of a video communication channel in homes of elderly people by a medium-sized Norwegian company. Presented from a firm perspective, this story provides an example of the challenges of the new technology development in this particular setting and learnings gained, while balancing new technology development with needs and feedbacks from users as well as market considerations. 
In Chapter 10 Elin M. Oftedal and Lene Foss discuss how responsible start-ups are dealt with by the health sector. Through following three Norwegian companies, the authors acquire insight into challenges the entrepreneurs experience when they introduce their technology/service to the healthcare sector.

Chapter 11 by Kornelia Konrad, Verena Schulze Greiving and Paul Benneworth describes the innovation process of an eHealth application which emerged as a user-driven, local project in the Netherlands. This chapter considers if and how the regional and partly local, bottom-up nature of the innovation network was conducive to enacting dimensions of responsibility.

In Chapter 12 Elisa Thomas and Luciana Maines da Silva analyse how two Brazilian digital health start-ups manage stakeholders' participation. Results show that the inclusion of stakeholders happens via tacit or explicit knowledge exchange, and that firms need different structures and routines to deal with different knowledge types to fully explore the potentials of inclusiveness.

Chapter 13 written by Bernard Naughton and Lene Foss explores how an academic entrepreneur pursues responsibility in commercializing research-based knowledge. Through a narrative based case study of a university professor employed at a mid-sized UK university, the authors provide insight into how a professor has performed digitalized healthcare practice research, innovation and commercialization.

Chapter 14 by Jill Kickul, Mark Griffiths and Marissa Titus investigates a digital therapeutics case from USA. They identify two major challenges for acceptance of digital therapeutics: proof of efficacy and consumer habits.

Our final chapter, Chapter 15, summarizes the need for responsible innovation in digital health. Far from being a burdensome requirement our research suggests that including users actively and early on in the design process can make a significant difference both to the quality of innovation and to its downstream acceptance. It allows early identification of unnecessary risks in implementing innovations. Through feedback from users and stakeholders designers can adapt and adjust business models, pivoting them to better fit the emerging context and meet the needs of diverse stakeholders. For policymakers the nature of the healthcare system and the ways in which procurement often take place offer a significant opportunity to shape innovation towards responsible trajectories which put the concerns of patients at the forefront.

We have tried in this book to offer evidence and examples of user inclusiveness, early anticipation of risks, reflectiveness of business models in digital innovations in health and welfare sectors. We observe these phenomena in different situations and variety, and within different international context. Whether we are speaking about user-driven innovations, or start-up sustainable models, or pathways to responsible innovation in mature organization, the same important issues of inclusivity, anticipation and responsiveness arise. We 
believe that a responsible innovation process can be a tool for users, clinicians, businesses and policymakers to create a system where the newest technology can be implemented to increase care for the patient and minimize cost for the care-provider.

\section{NOTE}

1. Empirical evidence comes from project 'Digitalize or Die - Dynamic Drivers of Responsible Research and Innovation in Health and Welfare services', funded by Norwegian Research Council, project number 247716/O70.

\section{REFERENCES}

Christensen, C., Waldeck, A. \& Fogg, R. (2017). How disruptive innovation can finally revolutionize healthcare. Innosight executive briefing, retrieved on 8 March 2019 from https:/www.christenseninstitute.org/wp-content/ uploads/2017/05/How-Disruption-Can-Finally-Revolutionize-Healthcare -final.pdf.

Cole, H. S. D., Freeman, C., Jahoda, M. \& Pavitt, K. L. R. (1973). Thinking about the Future: A Critique of 'Limits to Growth'. Published on behalf of Sussex University Press, London.

Gratton, L. \& Scott, A. (2016). The 100-Year Life: Living and Working in an Age of Longevity. London: Bloomsbury Publishing.

Hwang, J. \& Christensen, C. M. (2008). Disruptive innovation in health care delivery: a framework for business-model innovation. Health Affairs, 27(5), 1329-1335.

Keehan, S. P., Stone, D. A., Poisal, J. A., Cuckler, G. A., Sisko, A. M., Smith, S. D. ... \& Lizonitz, J. M. (2017). National health expenditure projections, 2016-25: price increases, aging push sector to 20 percent of economy. Health Affairs, 36(3), 553-563.

Marmot, M., Allen, J., Bell, R., Bloomer, E. \& Goldblatt, P. (2012). WHO European review of social determinants of health and the health divide. The Lancet, 380(9846), 1011-1029.

Oliveira, P., Zejnilovic, L., Azevedo, S., Rodrigues, A. M. \& Canhão, H. (2018). Peer-adoption and development of health innovations by patients - a national representative study of 6204 citizens, JMIR Preprints. 30/07/2018:11726, doi: 10.2196/preprints.11726, http://preprints.jmir.org/ preprint/11726.

Owen, R., Bessant, J. \& Heintz, M. (eds) (2013). Responsible Innovation: Managing the Responsible Emergence of Science and Innovation in Society. Chichester: John Wiley \& Sons. 
Stilgoe, J., Owen, R. \& Macnaghten, P. (2013). Developing a framework for responsible innovation. Research Policy, 42(9), 1568-1580.

von Schomberg, R. (2011). Towards responsible research and innovation in the information and communication technologies and security technologies fields. A Report from the European Commission Services, Directorate General for Research and Innovation, Luxembourg: Publications Office of the European Union, 2011, retrieved on 8 March from http://ec.europa.eu/ research/science-society/document_library/pdf_06/mep-rapport-2011_en .pdf. 